\title{
Strategic Interactions on Structural Reforms Between Integrated Economies: What Lessons for the EU?
}

\author{
Etienne Lehmann \\ University of Paris 2 - Panthéon-Assas \\ Emmanuelle Taugourdeau \\ University of Paris 1 - Panthéon-Sorbonne
}

\begin{abstract}
We show that the domestic output increases with a foreign country's structural reform and decreases with foreign country's fiscal policy. Hence, when governments act non-cooperatively, they implement too low structural reforms and too much fiscal policies.

- JEL Classifications: E61, F42, H87

- Key words: Coordination failures, Aggregate supply, Aggregate demand, Structural reforms
\end{abstract}

\section{Introduction}

The persistence of unemployment is one of the most pressing problems in EU (European Union) nowadays. One should therefore wonder what are the consequences of the European Economic Integration (EEI) on the unemployment level. This question is rather wide, one aspect being the influence of EEI on the incentives for governments to apply structural reforms.

\footnotetext{
*Corresponding address: Professor Etienne Lehmann, ERMES - University Paris II Panthéon Assas 26 rue des fossés St. Jacques 12 place du Panthéon, 75230 Paris France cedex 05. Tel: +33-1-44-41-89-70, Fax: +33-1-40-51-81-30, E-mail: elehmann@u-paris2.fr, Web: http://www.u-paris2.fr/ermes/membres/lehmann/ lehmann.htm, also on the faculty of CREUSET - University Saint Etienne, and EUREQua-University Paris I. "Professor Emmanuelle Taugourdeau, Maiso des Sciences Economiques, 106-112 Boulevard de l'Hôpital, 75 647 Paris Cedex 13, E-mail: taugour@univ-paris1.fr (C2004-Center for International Economics, Sejong Institution, All Rights Reserved.
} 
The literature usually considers the EEI as the loss of autonomy of monetary policy (EMU for European Monetary Union) and the limitation of fiscal instruments (The Amsterdam Treaty) for national policymakers (see among others Bean (1998a) and (1998b), Sibert and Sutherland (2000), Bentolila and Saint-Paul (2000), Calmfors (2001)). The incentives to undertake structural reforms on the labor market can then be increased or reduced in the EMU depending on the type of reforms considered.

However, we consider the EEI is not reduced to the EMU and the Amsterdam Treaty. Actually, the Unique European Act by accelerating exchanges and capital flows, has reinforced the externalities implied by a policy in one country on other countries' economic performances. Hence, one should identify the nature of these external effects and its consequences on the policies chosen by governments that play non-cooperatively. We raise this question in a medium run perspective in which structural reforms are the only policies that affect output if government cooperate.

For this purpose, we develop a two-country "Aggregate Supply/Aggregate Demand" framework in which we assume that nominal wages fit to a purchase power objective. We show that a structural reform of the domestic labor market improves the foreign economy through a fall of the terms of trade. Conversely, a fiscal policy in one country reduces the foreign economy through an increase of the terms of trade. There are therefore too little labor market reforms and too much fiscal policy when governments play non-cooperatively.

Section 2 presents the two-country model. The Nash equilibrium is explored in section 3. The last section concludes.

\section{The Economy}

We consider a two-country log-linear "Aggregate Supply/Aggregate Demand" framework, in which countries $A$ and $B$ are symmetric. $y_{i}, g_{i}$ and $s_{i}$ respectively denote the logarithm of the output, of public expenditures and the level of flexibility of the labor market in country $i=A, B$. The EEI guarantees a high degree of capital mobility which implies that the real interest rate $r$ is the same in the two countries. ${ }^{1}$ Finally, $x$ is the logarithm of the terms of trade for country $A$,

\footnotetext{
'The "medium term" horizon we consider differs from a "long term" horizon by the fact that we assume that capital stock is predetermined in each country. The perfect mobility of capital thus changes only future capital stock and not current one.
} 
so $-x$ denotes the terms of trade for country $B$. In each country, the good market equilibrium is represented by:

$$
y_{A}=\alpha g_{A}-\beta x-\gamma r \quad y_{B}=\alpha g_{B}+\beta x-\gamma r \quad \alpha, \beta, \gamma>0
$$

This specification implies that a fiscal policy (rise of $g$ ) in one country increases goods demand, whereas an increase of $r$ reduces demand by lowering investments in both countries. A rise of the terms of trade $x$ corresponds to a decrease in the price-competitiveness of country $A$ 's and to a rise in country $B$ 's one. It thus reduces country $A$ exportations and increases country $B$ exportations, if one assumes that the Marshall-Lerner conditions are verified. ${ }^{2}$

In each country, the aggregate supply is a decreasing function of the real wage. The real wage corresponds to the ratio between the nominal wage $W$ and the production price $P$. We explore a "medium-term" framework in which nominal wage adjusts itself so as to guarantee a purchase power $\omega$ to workers. Nominal wage then equals to the product of workers' objective of purchase power $\omega$ to the consumption price index $P_{c}$. We get then $W=\omega P_{c}$ so $W / P=\omega\left(P_{c} / P\right)$. A rise in the terms of trade reduces the ratio of the consumption price index to the production one, so real wage increases with the terms of trade. The aggregate supply is thus increasing in $x$ in country $A$ and decreasing in $x$ in country $B$, which can be summarized by:

$$
y_{A}=s_{A}+\varepsilon x \quad y_{B}=s_{B}-\varepsilon x \quad \varepsilon>0
$$

A country $i$ structural reform takes the form of a rise in $s_{i}$. It may either consists of a decrease in workers' objective of power parity $\omega$, or of a production reorganization that ceteris paribus increases labor productivity and therefore aggregate supply.

The equality between relative demand $\left(y_{A}-y_{B}\right.$ from equations (1)), and relative supply $\left(y_{A}-y_{B}\right.$ from equations (2)) determinates the terms of trade:

$$
x=\frac{\alpha\left(g_{A}-g_{B}\right)+s_{B}-s_{A}}{2(\beta+\varepsilon)}
$$

From equations (2) and (3), we deduce the production in each country: $y_{i}=Y\left(s_{i}\right.$, $\left.s_{j}, g_{i}, g_{j}\right)$ with $i, j=(A, B)$ or $(B, A)$ and $^{3}$ :

\footnotetext{
${ }^{2}$ This specification of the demand function is a reduced form of an IS equation that is compatible with the hypothesis of positive interactions from the level of output of one country on the demand for good of the other country.

${ }^{3}$ The hypothesis of real rigidity of wage implies that in this model, money has no effect on real variables. That is the reason why we do not explicit the market of money.
} 


$$
Y\left(s_{i}, s_{j}, g_{i}, g_{j}\right)=\frac{(2 \beta+\varepsilon) s_{i}+s_{j}-\alpha \varepsilon\left(g_{i}-g_{j}\right)}{2(\beta+\varepsilon)}
$$

The real interest rate is finally given by:

$$
r=\frac{\alpha\left(g_{A}+g_{B}\right)-\left(s_{A}+s_{B}\right)}{2 \gamma}
$$

In a closed economy, one has $\varepsilon=0$ so the terms of trade are exogenous. Real rigidities imply that fiscal policy has no impact on output. Output depends only on domestic structural reforms and is therefore independent of structural reforms in the other country, as well as fiscal policies in both countries, so ${ }^{4} Y_{1}^{\prime}=1$ and $Y_{2}^{\prime}=Y_{3}^{\prime}=Y_{4}^{\prime}=0$. In our model, these results do not hold anymore because of trade exchanges between countries. A structural reform in country $A$ increases its supply relatively to country $B$ 's one. The terms of trade $x$ therefore decrease (cf. equation (3)), which moderates the positive impact on country's A output $y_{A}$ and implies a rise in country's $B$ output $y_{B}$ (cf. equation (2)). Furthermore, a rise in the world demand should correspond to the rise in the world supply. This happens through a decrease in interest rate that increases investments in both countries (cf. equation (5)). Consequently, $0<Y_{2}^{\prime}<Y_{1}^{\prime}<1$.

When country $A$ increases its public expenditures, demand for country $A$ 's good increases relatively to country $B$ 's one, so the terms of trade increase. The aggregate supply and thereby the output increase in country $A$ but decline in country $B$, so $Y_{4}^{\prime}<0<Y_{3}^{\prime}$. The interest rate rises and investments decrease in both countries.

Remark that cross effects are only due to the terms of trades in aggregate supply equations (2). If real wages were independent of the terms of trade (i.e. if $\varepsilon=0$ ), as it is the case for closed economy, we would have $y_{\mathrm{A}}=s_{A}$ and $y_{\mathrm{B}}=s_{B}$.

We now specify the political objectives $\Omega_{A}$ and $\Omega_{B}$ pursued by governments $A$ and $B$. We assume that objectives are symmetric and depend on outputs, public expenditures as well as domestic structural reforms, according to:

$$
\Omega_{i}=y_{i}-\frac{1}{2 \Sigma}\left(s_{i}\right)^{2}-\frac{1}{2 \Gamma}\left(g_{i}-\bar{g}\right)^{2} \text { with } \Sigma, \Gamma>0
$$

In choosing the level of fiscal policy, the government considers two direct effects of public expenditures on welfare, and one indirect. First, a rise of public expenditures

\footnotetext{
${ }^{4}$ For any twice differentiable function $f(., \ldots,$.$) , we denote as f_{i}^{\prime}(., \ldots,$.$) the derivative of f$ with respect to its $i^{\text {th }}$ argument, and as $f^{\prime \prime}{ }_{i j}(., \ldots .$.$) the second derivative of f(., \ldots .$.$) with respect to its i^{\text {th }}$ and $j^{\text {th }}$ arguments.
} 
increases public good, but second, it decreases ceteris paribus private consumption through an increase in tax rates. Finally, given the foreign fiscal policy, it increases the aggregate output trough a rise in the terms of trade. $\bar{g}$ then represents the optimal trade-off between the two first effects. Hence, the government's objective $\Omega_{i}$ increases in the level of domestic output $y_{i}$, decreases with the implementation of a structural reform $s_{i}$ and decreases with the distance between actual fiscal policy $g_{i}$ and $\bar{g}$.

Replacing production in equation (6) we get payoff functions which depend on structural and fiscal policies only:

$$
V_{i}\left(s_{i}, s_{j}, g_{i}, g_{j}\right)=\frac{2(\beta+\varepsilon) s_{i}+\varepsilon s_{j}+\alpha \varepsilon\left(g_{i}-g_{j}\right)}{2(\beta+\varepsilon)}-\frac{1}{2 \Sigma}\left(s_{i}\right)^{2}-\frac{1}{2 \Gamma}\left(g_{i}-\bar{g}\right)^{2}
$$

\section{Inefficiency of Nash Equilibrium}

In this section, we analyze the coordination failures in structural and fiscal policies. Without any kind of coordination, each government determinates its structural policy in order to maximize its payoff function taking the policies of the foreign country as given. At the symmetric Nash equilibrium we get:

$$
s^{N}=\frac{2 \beta+\varepsilon}{2(\beta+\varepsilon)} \Sigma \quad g^{N}=\bar{g}+\frac{2 \beta+\varepsilon}{2(\beta+\varepsilon)} \Gamma \quad \text { and } \quad y^{N}=s^{N}
$$

In order to evaluate the coordination failures, we compare the non-cooperative game with the cooperative result. The symmetric cooperative equilibrium solves:

$$
\max _{s_{A}, s_{B}, g_{A}, g_{B}} W\left(s_{A}, s_{B}, g_{A}, g_{B}\right) \equiv V\left(s_{A}, s_{B}, g_{A}, g_{B}\right)+V\left(s_{B}, s_{A}, g_{B}, g_{A}\right)
$$

The first order conditions imply:

$$
s^{C}=\Sigma \quad g^{C}=\bar{g} \quad \text { and } \quad y^{C}=s^{C}
$$

Immediately we observe that:

$$
s^{N}<s^{C} \quad \text { and } g^{N}>g^{C}
$$

Since $Y_{2}^{\prime}>0$, the Nash equilibrium exhibits positive spillovers for structural reforms, that is $V_{2}^{\prime}>0$. Following Cooper and John (1988), this implies that governments implement too little structural reform at Nash equilibrium, because without coordination, governments do not take into account the positive effects of domestic labor market reform on foreign country's output. 
The lack of fiscal policy coordination leads to an excessive level of public expenditures. A rise of public expenditure increases the country $A$ output by a country $B$ output reduction which constitutes a negative spillover $V_{4}^{\prime}<0$. Then, without coordination, governments do not take into account the negative impact on country $B$ 's output and fix too much public expenditures.

At the Nash equilibrium, the output is consequently lower in the two countries $y^{N}<y^{C}$ and interest rate is higher $r^{N}>r^{C}$. Finally the payoff functions are higher at cooperative equilibrium than at non cooperative equilibrium since $\left(s^{\mathrm{C}}, g^{C}\right)$ maximizes $V(s, s, g, g)$.

\section{Conclusion}

This article highlights coordination failures between interdependent countries. The comparison between Nash equilibrium and cooperative equilibrium shows that uncoordinated governments implement too little structural reform and too much fiscal policy: this is because national governments underestimate the global benefits from national structural reforms and overestimate the global benefits from national fiscal policies. One implication of this model is that EEI should not be restricted to monetary issues (EMU) or fiscal issues (the Amsterdam Treaty), but should also concern structural aspects such as labor market regulations.

The model can also explain the attitude of cooperation organisms to encourage structural reforms and to discourage fiscal policies. This is particularly the case for the commission of the European Union. For instance, European Union (2002) recommends "to achieve budgetary positions close to balance or in surplus as soon as possible in all Member States and at the latest by 2004" (page 8). Furthermore, the same council recommends to "invigorate labor markets" by structural reforms (for details see page 16). Similar recommendations can be found in OECD (1999, chapter 4) concerning labor market reforms.

An interesting extension of this paper would relax the assumption of symmetric countries. This hypothesis allows a clear definition and tractable determination of the cooperative equilibrium because it cancels any conflict of interest between countries with heterogeneous preferences for public expenditures or for labor market reforms. However, such heterogeneity actually exists and plays an important role. For instance, within the EU, it seems that a country such as UK is characterized by a lower aversion for labor market reform than countries such as France, and by a lower taste for public expenditures than countries such as 
Sweden. An extension of this model should then integrate the issue of designing policy coordination between heterogeneous countries, a topic that belongs to our research agenda (Taugourdeau, (2002)).

\section{Acknowledgements}

We wish to thank Hubert Kempf, Sebastien Vivier-Lirimont and an anonymous referee for their helpful comments. Any remaining error remains our.

Received 19 March 2002, Accepted 23 October 2002

\section{References}

Bean, C. (1998a) Monetary Policy under EMU, Oxford Review of Economic Policy, 14, 41-53.

Bean, C. (1998b) The Interaction of Aggregate Demand Policies and Labor Market Reform, Swedish Economic Policy Review, 5, 353-382.

Bentolila, S. and Saint-Paul, G. (2000) Will EMU increase Eurosclerosis?, CEPR Discussion Paper, 2423.

Calmfors, L (2001) Unemployment, Labour-Market and Reform and Monetary Union, Journal of Labor Economics, 19(2), 265-289.

Cooper, R. and John, A. (1988) Coordinating coordination failures in keynesian models. Quarterly Journal of Economy, 103, 441-463.

European Union (2002) Council recommendation of 21 June 2002 on the broad guidelines of the economic policies of the member states and the community, http://ue.eu.int/ emu/en/index.htm

OECD (1999) Economic Outlook, OECD.

Sibert, A. and Sutherland, A. (2000) Monetary Union and Labor Market Reform, Journal of International Economics, 51, 421-435.

Taugourdeau, E. (2002), Is fiscal cooperation always sustainable when regions differ in size? forthcoming in Annales d'Economie et de Statistiques Cahiers de la MSE, 2002-27, http://www.univ-paris1.fr/MSE/CahiersMSE 